\title{
Preparation of Chitooligosaccharide Mesh Graft using Freeze Gelation Method: Wound Dressing against Diabetic Foot Ulcers Pathogens
}

\author{
P. Vanathi* \\ Assistant Professor \& Head, PG and Research Department of Biotechnology, Sengunthar Arts and Science College, \\ Tiruchengode, Namakkal -637205, Tamil Nadu, India; vanathisekar3@gmail.com
}

\begin{abstract}
The importance of chronic wound treatment is with the management of the wound bed providing a moist environment to enhance epithelialisation in the wound healing process. The demand for the development of effective wound dressing in a cost effective condition is increasing day by day. On these points in view the present study was focused on to the preparation of the polymeric graft dressings based on chitosan for safer and reliable wound care management. In this regard to prepare chitosan based wound dressing the enzymatic degradation of chitosan was undertaken. The partially purified enzyme sample was taken for the degradation of the chitosan for the preparation the bioactive chitooligosaccharide. COS:PVA:collagen graft was prepared with the aldehyde compound. The wound scratching assay and the antimicrobial activity of the prepared graft has proved its antimicrobial and biocompatibility of the prepared graft.
\end{abstract}

Keywords: Antimicrobial Activity, Chitooligosaccharides, Chitosan, Freeze Gelation Method, Wound Scratch Assay

\section{Introduction}

The infections in the diabetic foot are usually due to aerobic bacteria, anaerobes and Candida spp. The severe infections are by polymicrobial isolates, whereas the milder infections are generally monomicrobial ${ }^{1}$. E. coli, Proteus, Pseudomonas spp., S. aureus and Enterococcus spp. are the most frequent pathogens of diabetic foot ulcers? An ideal wound dressing should be biocompatible and biodegradable to enhance the healing process must be comfortable and acceptable for the patient ${ }^{\underline{3}}$. Traditional dressings used for the management of wounds have limited swelling capacity and moisture vapor permeability. Dressings for wounds have been engineered to facilitate wound healing ${ }^{4}$. Application of engineered skin equivalents or combinations of growth factor application and skin grafts or isolated epithelial cells is good biological approaches in wound area ${ }^{5}$. In recent years a large number of research are focused on to produce a new and improved wound dressing with biocompatible materials ${ }^{\underline{6}}$. The practical use of conventional wound dressings is limited due to the allergenic nature of the materials or use of organic solvents in the manufacturing process. Hence synthetic polymers are replaced by replenishable, natural resources ${ }^{\mathrm{Z}}$.

Chitosan and its oligosaccharides (COS with an average molecular weight below $3.9 \mathrm{kDa}$ ) have unique biological properties, one among is water-soluble oligomers, biodegradable and non-toxic ${ }^{\underline{8}}$. Several methods have been reported for the preparation of COS from chitosan, including enzymatic degradation.

The utilization of the marine chitinous wastes is an inexpensive source for the enzyme production? ${ }^{2}$ for the conversion of chitosan to $\operatorname{COS}$ using chitosanase

*Author for correspondence 
enzyme ${ }^{10}$. The complex purification steps could be overcome by $\underline{11}$ using the enzymatic hydrolysates of chitosanoligosaccharides for the extensive application. These formed the basis for the present investigation; hence the present work was concentrated on the chitooligosaccharide enzymatic hydrolysates mesh graft as the dressings against diabetic foot ulcers.

\section{Materials and Method}

Chitosan (1\% wt/vol) was dissolved in $1 \%$ acetic acid (vol/vol) (99-100 \%) and was kept in shaker at $100 \mathrm{rpm}$ for $2 \mathrm{~h}$ at room temperature $\left(25^{\circ} \mathrm{C}\right)$ to obtain homogeneous solution.

\subsection{Sample Collection and Screening of the Chitosanase Producing Organism}

The bio wastes soil samples rich in chitin sources such as chicken feather and poultry waste dumped soil were collected from various places of Tamil Nadu. From the prepared suspension, the chitosanase activity can be indicated by the clear zone formed on the CDA plates and the selected strains with clear zone were cultivated on $\mathrm{M} 9$ broth at $30^{\circ} \mathrm{C}$ for 5 days $\frac{12}{}$. The culture broth of 3 $\mathrm{ml}$ was collected and centrifuged for $15 \mathrm{~min}$ at $6000 \mathrm{rpm}$, after centrifugation supernatant was used for the enzyme analysis by 3,5-Dinitrosalicylic method $\frac{13}{}$. The strains were selected for the further study based on the highest chitosanase activity and partial purification of enzyme was done by ammonium sulfate fractionation.

\subsection{Preparation of Chitooligosaccharides}

About $1 \mathrm{ml}$ of the partially purified chitosanase was added to $1 \mathrm{ml}$ of $1 \%$ chitosan and incubated at $45^{\circ} \mathrm{C}$ for $30 \mathrm{~min}$. The reaction was stopped by heating at $100^{\circ} \mathrm{C}$ and then precipitating with $0.25 \mathrm{M}$ of sodium hydroxide ${ }^{\underline{14}}$ after cooling. The bioactive chitooligosaccharide mixture was prepared by varying the incubation time of $1 \%$ chitosan with partially purified enzyme from $10 \mathrm{~min}$ to $48 \mathrm{hr}$ against the pathogens.

\subsection{Mesh Graft Preparation - Preparation of a Chitooligosaccharide Mesh Graft by using Freeze-gelation Method}

Freeze gelation $\underline{15}, \underline{16}$ was used to prepare chitooligosaccharide mesh graft.

\subsection{In vitro Antibacterial Test}

The antibacterial performance of the COSs scaffolds was assessed by an in vitro bacterial culture. About 100 $\mu \mathrm{L}$ of Staphylococcus aureus, E. coli in nutrient broth suspension with a concentration of $10^{5}-10^{7} \mathrm{CFU} / \mathrm{mL}$ was swabbed on a nutrient agar plate separately. The scaffold was cut as per standard size $(5 \mathrm{~cm} \mathrm{X} 2.5 \mathrm{~cm})$ and placed over the inoculated test bacterial cultures. The plates were kept for incubation at $37^{\circ} \mathrm{C}$ for $24 \mathrm{~h}$ and zone of incubation formed around the film was recorded in millimetres.

\subsection{Wound Healing Assay of Chitooligosaccharide PVA: Collagen-in vitro Wound Scratch Assay ${ }^{17,18}$}

The in vitro scratch assay was used to study cell migration in vitro and the cell proliferation was monitored at 0,24 and $48 \mathrm{~h}$ and images of the migrated cells were studied points by inverted phase contrast microscope. Extent of wound healing was determined by the distance traversed by cells migrating into the denuded area.

\section{Result and Discussion}

\subsection{Screening of the Chitosanase Producing Organism and Chitosanase Enzyme Activity}

The chitosanase activity was indicated by the clear zone observed in the CDA. During screening, the higher zone producing colonies were chosen and subjected to secondary studies. Growth was observed in CDA plates of chitosan after 3 days was in agreement with reports of Abdel-Aziz S et al (2012) $)^{\frac{19}{9}}$ for the isolation of chitosan degrading organism. The clear zone observed in CDA plates aligned with the results of Cheng and $\mathrm{Li}(2000)^{\frac{12}{2}}$, on the screening of the microbial colonies on CDA plates.

The maximal specific chitosanase activity was observed on the fourth day of incubation and tends to decrease slowly from the fifth day. The higher enzyme activity showed areas that were subjected for the partial purification by dialysis.

\subsection{Preparation of Chitooligosaccharides}

The partially purified chitosanolytic enzymes produced by the isolates was used to hydrolyze $1 \%$ chitosan solution at different incubation time. The chitosan solution was hydrolysed with chitosanase enzyme of the isolates at 180 
Table 1. Antimicrobial activity of the chitooligosaccharide hydrolysate

\begin{tabular}{|c|c|c|c|c|c|c|c|c|c|c|c|c|}
\hline \multirow{3}{*}{ Isolates 10 } & \multicolumn{8}{|c|}{ Different incubation time of the hydrolysate (minutes and hours) } \\
\cline { 2 - 13 } & 30 & 60 & 90 & 120 & 150 & 180 & 210 & 240 & 480 & 510 & 24 hrs & 48 hrs \\
\hline S9 & + & + & + & + & + & ++ & +++ & ++ & + & + & + & - \\
\hline
\end{tabular}

- Indicates no inhibition; + Indicates low inhibition; ++ Indicates medium inhibition; +++ Indicates higher inhibition.

min have shown to possess a prominent antimicrobial activity (Figure 1) than the hydrolysate obtained at other time intervals.

The chitooligosaccharides prepared from the enzymatic hydrolysis with chitosanase was checked for its antimicrobial activity against E, coli, S. aureus, Pseudomonas sp, and Candida albicans. The chitooligosaccharide prepared at the 180 min showed to have the antimicrobial activity and were then subjected to check its antibacterial activity at concentration of $100 \mu \mathrm{l}$ of $1 \mathrm{mg} / \mathrm{ml}$ against foot ulcer pathogens (Table 1).

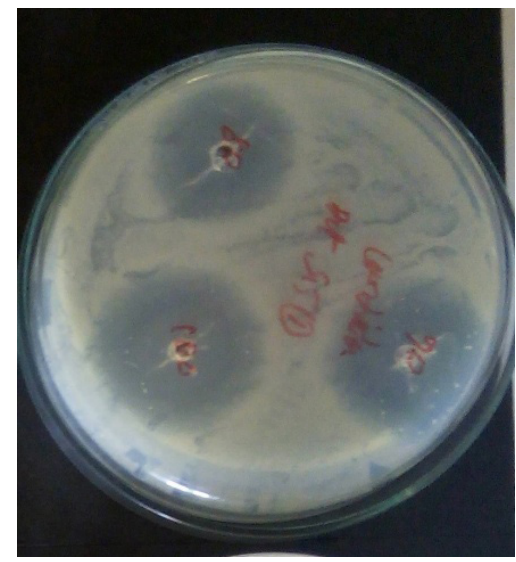

Figure 1. Antimicrobial activity of chitooligosaccharides against Candida sp by well diffusion method.

Chitooligosaccharides prepared (Figure 2) by partial hydrolysis of chitosan provide an important biologically active derivative $\underline{20}$ was supporting our results. The enzymatic hydrolysate consists of mixtures of oligomers $\underline{21}$ and increasing concentration of the monomer concentration inverselyproportionate in the concentration of tetramers and pentamers with hydrolysis time and vice $\operatorname{versa}^{22}$. As per the report of $\frac{23}{3}$ the antimicrobial activity of the monomer is lesser in comparison with mixture which again matched with the results of the study that the hydrolysates antimicrobial activity decreases with the hydrolysis time and the reason might be due to the increase in the monomer concentration. Hence for the chitooligosaccharide preparation in the present study hydrolysation with chitosanase enzyme of the isolates was fixed at $45^{\circ} \mathrm{C}$, pH 5.5 for $180 \mathrm{~min}$.

\subsection{Chitooligosaccharide Mesh Graft}
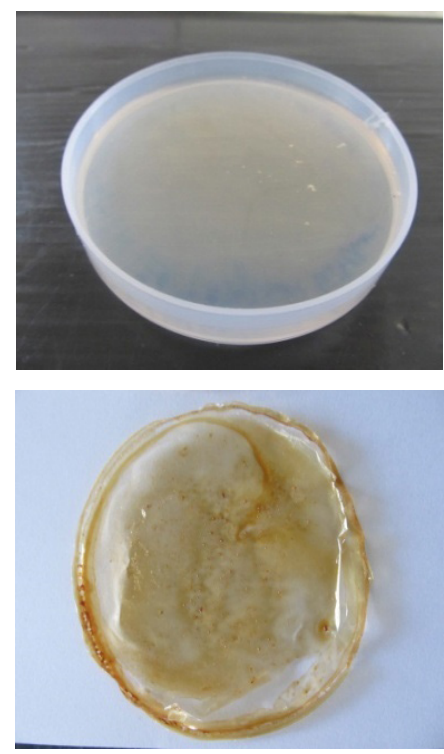

Figure 2. Chitooligosaccharide mesh graft preparation.

The addition of chitooligosaccharides provides an additional amino group which function as binding sites to increase the GA collagen cross-linking efficiency. Hence, the collagen and chitooligosaccharide is crucial 24,25 good combination for developing as a wound healer. GA was used in the preparation to improve their bio stability.

\subsection{In vitro Antibacterial Activity of Chitooligosaccharide Mesh Graft}

The antibacterial performance of the COS mesh graft was assessed by an in vitro bacterial culture. The COS zone 
of inhibition for staphylococcus aureus was $31 \mathrm{~mm}$ and the zone of inhibition for E. coli was $50 \mathrm{~mm}$ (Figure 3). It was clear that the COS graft showed stronger antibacterial activity against $E$. coli than $S$. aureus. Further higher antibacterial activity than those reported by Prunieras, $M$. et al. (1979) $\frac{18}{}$. This observation may be due to the higher deacetylation degree of COS which implies a higher number of side amine groups available for reaction.

Table 2. Antibacterial assessment of mesh graft by AATCC 147 test method

\begin{tabular}{|c|c|c|c|}
\hline \multirow{2}{*}{ S. No } & \multirow{2}{*}{ Sample } & \multicolumn{2}{|c|}{ Zone of Inhibition (mm) } \\
\cline { 3 - 4 } & & E. coli & S. aureus \\
\hline 1 & $\begin{array}{c}\text { COS Mesh } \\
\text { graft }\end{array}$ & 50 & 31 \\
\hline
\end{tabular}

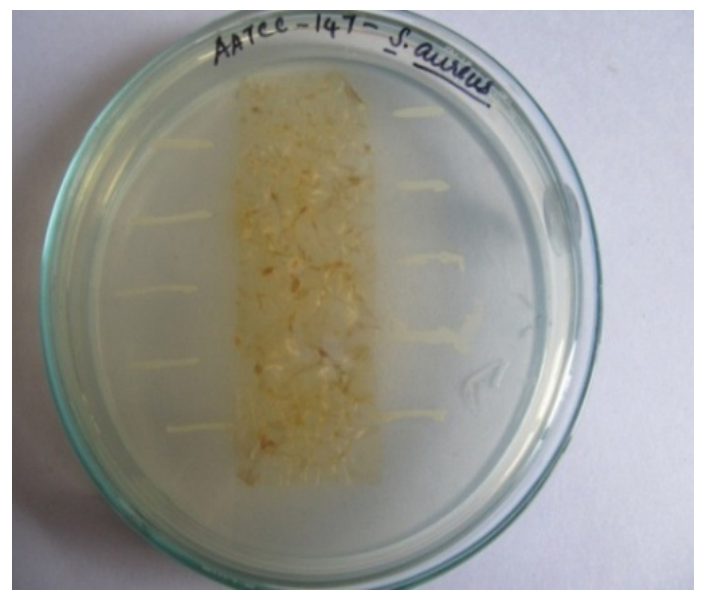

Figure 3. Antibacterial assessment of mesh graft by AATCC 147 test method.

\subsection{Wound Healing Assay of Chitooligosaccharide Graft: In vitro Wound Scratch Assay}

The ability to improve healing by acting directly on fibroblast cells, after $24 \mathrm{hr}$ and $48 \mathrm{hr}$ of wounding, Chito oligosaccharide:PVA:Collagen treated fibroblast cells had higher rates of wound closure than untreated fibroblast cells (Figure 4) with the faster rate of cell migration and proliferation induced cell migration away from the edge of the cell monolayer and towards the wounded area. These data were also supported by the previous reports of Qi

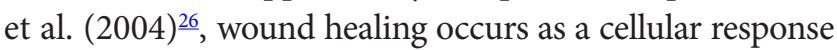
activation of fibroblast and endothelial cells. The results of the current study demonstrate chitooligosaccharide collagen graft promote the wound healing activity by restoring the fibroblast proliferation.

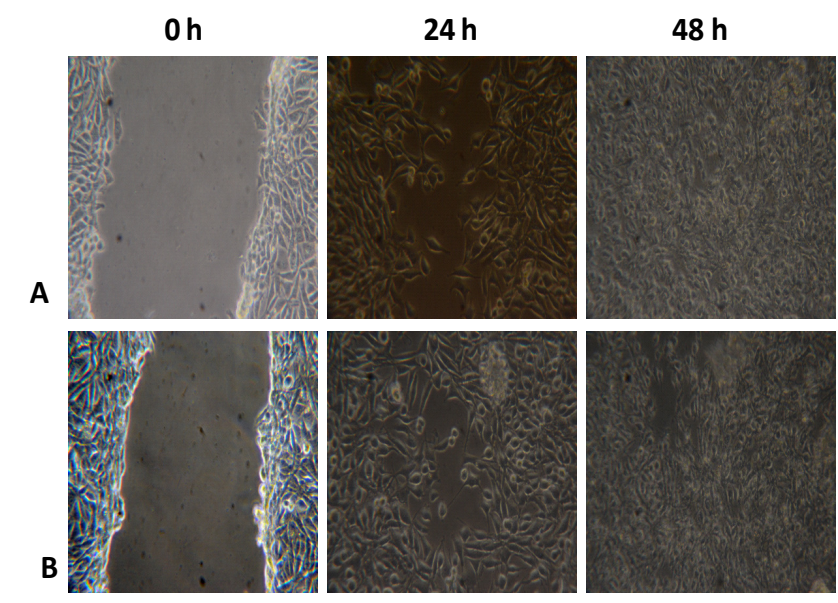

Figure 4. Chitooligosaccharide:PVA:collagen (3:2:1) promotes wound healing by scratch assay method (A) chitooligosaccharide: PVA: collagen (3:2:1) treated cultures (B) untreated cells.

COS:PVA:collgen (3:2:1) showed remarkable activity related to scratch wound healing. Thus chitooligosaccharides and collagen can be combined can create new materials with unique structural and mechanical properties appropriate for tissue regeneration. The data was in par with the previous reports of Qi et al $(2004)^{26}$.

Here in the present study chitooligosaccharide hydrolysates graft can be considered suitable for the wound healing therapy. COS hydrolysate will be adding a new dimension as a wound healing agent against the pathogens which were developed by the enzymatic preparation from the bio waste sample.

\section{Conclusion}

The results indicate that chitinous wastes could be used in the production of chitosanase enzyme. Partial degradation of oligosaccharide are less cost effective in using a chitooligosaccharide wound dressing instead of purified form. The cost effective methodology and green technology adapted will offer low cost biomedical superficial COS wound dressing as an alternative for the available technologies. Hence the development of commercial biodegradable wound dressing materials preparation in junction with COS as a base membrane matrix will be the next objective for further research. 


\section{References}

1. Mohanasoundaram KM. The microbiological profile of diabetic foot infections. J Clin Diagn Res. 2012; 6(3): 409-11.

2. Raja NS. Microbiology of diabetic foot infections in a teaching hospital in Malaysia: A retrospective study of 194 cases. Journal of Microbiology Immunology and Infection. 2007; 40(1): 39-44. PMid: 17332905.

3. Hilton JR, Williams DT, Beuker B, Miller DR, Harding KG. Wound dressings in diabetic foot disease. Clinical Infectious Diseases. 2004; 39(S2): S100-3. PMid: 15306987. https://doi.org/10.1086/383270

4. Upton Z, Cuttle L, Noble A, Kempf M, Topping G, Malda J, Xie Y, Mill J, Harkin DG, Kravchuk O, Leavesley DI. Vitronectin: Growth factor complexes hold potential as a wound therapy approach. Journal of Investigative Dermatology. 2008; 128(6): 1535-44. PMid: 18200066. https:// doi.org/10.1038/sj.jid.5701148

5. Wood FM, Kolybaba ML, Allen P. The use of cultured epithelial autograft in the treatment of major burn injuries: A critical review of the literature. Burns. 2006; 32(4): 395-401. PMid: 16621307. https://doi.org/10.1016/j. burns.2006.01.008

6. Draye JP, Delaey B, Van de Voorde A, Van Den Bulcke A, De Reu B, Schacht E. In vitro and in vivo biocompatibility of dextran dialdehyde cross-linked gelatin hydrogel films. Biomaterials. 1998; 19(18): 1677-87. https://doi. org/10.1016/S0142-9612(98)00049-0

7. Tharanathan RN. Biodegradable films and composite coatings: Past, present and future. Trends in Food Science and Technology. 2003; 14(3): 71-8. https://doi.org/10.1016/ S0924-2244(02)00280-7

8. Kim SK, Rajapakse N. Enzymatic production and biological activities of chitosan oligosaccharides (COS): A review. Carbohydrate Polymers. 2005; 62(4): 357-68. https://doi.org/10.1016/j.carbpol.2005.08.012

9. Chasanah E, Patantis G, Zilda DS, Ali M, Risjani Y. Purification and characterization of Aeromonas media KLU 11.16 chitosanase isolated from shrimp waste. Journal of Coastal Development. 2012; 15(1): 104-14.

10. Yoon HG, Kim HY, Kim HK, Hong BS, Shin DH, Cho HY. Thermostable chitosanase from Bacillus sp. strain CK4: Its purification, characterization and reaction patterns. Bioscience, Biotechnology and Biochemistry. 2001; 65(4): 802-9. PMid: 11388456. https://doi.org/10.1271/bbb.65.802

11. Yoon HG, Kim H, Lim YH, Kim HK, Shin DH, Hong BS, Cho HY. Thermostable chitosanase from Bacillus sp. Strain CK4: Cloning and expression of the gene and characterization of the enzyme. Applied and Environmental Microbiology. 2000; 66(9): 3727-34. PMid: 10966383 PMCid: PMC92213. https://doi.org/10.1128/AEM.66.9.3727-3734.2000

12. Cheng CY, Li YK. An Aspergillus chitosanase with potential for large-scale preparation of chitosan oligosaccharides. Biotechnology and Applied Biochemistry. 2000; 32(3): 197-203. PMid: 11115392. https://doi.org/10.1042/

\section{BA20000063}

13. Miller GL. Use of dinitrosalicylic acid reagent for determination of reducing sugar. Analytical Chemistry. 1959; 31(3): 426-8. https://doi.org/10.1021/ac60147a030

14. Zhang H, Du Y, Yu X, Mitsutomi M, Aiba SI. Preparation of chitooligosaccharides from chitosan by a complex enzyme. Carbohydrate Research. 1999; 320(3): 257-60. https://doi. org/10.1016/S0008-6215(99)00154-8

15. Ho MH, Kuo PY, Hsieh HJ, Hsien TY, Hou LT, Lai JY, Wang DM. Preparation of porous scaffolds by using freeze-extraction and freeze-gelation methods. Biomaterials. 2004; 25(1): 129-38. https://doi.org/10.1016/S01429612(03)00483-6

16. Hsieh CY, Tsai SP, Ho MH, Wang DM, Liu CE, Hsieh $\mathrm{CH}$, Tseng $\mathrm{CH}$, Hsieh $\mathrm{HJ}$. Analysis of freeze-gelation and cross-linking processes for preparing porous chitosan scaffolds. Carbohydrate Polymers. 2007; 67(1): 124-32. https:// doi.org/10.1016/j.carbpol.2006.05.002

17. Liang CC, Park AY, Guan JL. In vitro scratch assay: A convenient and inexpensive method for analysis of cell migration in vitro. Nature Protocols. 2007; 2(2): 329-33. PMid: 17406593. https://doi.org/10.1038/nprot.2007.30

18. Prunieras M, Regnier M, Schloterrer M. Nouveau procede de culture des cellules epidermiques humaines sur derme homologue ou heterologue: Preparation de greffons recombines. Ann Chir Plast. 1979; 24: 357-62. PMid: 398182.

19. Abdel-Aziz S, Moharam M, Hamed H, Mouafi F. Extracellular metabolites produced by a Novel Strain. Bacillus alvei NRC-14: 1. Some Properties of the Chitinolytic System. New York Sci J. 2012; 5: 53-62.

20. Qin C, Li H, Xiao Q, Liu Y, Zhu J, Du Y. Water-solubility of chitosan and its antimicrobial activity. Carbohydrate Polymers. 2006; 63(3): 367-74. https://doi.org/10.1016/j. carbpol.2005.09.023

21. Kim JY, Lee JK, Lee TS, Park WH. Synthesis of chitooligosaccharide derivative with quaternary ammonium group and its antimicrobial activity against Streptococcus mutants. International Journal of Biological Macromolecules. 2003; 32(1):23-7. https://doi.org/10.1016/S01418130(03)00021-7

22. De Assis CF, Costa LS, Melo-Silveira RF, Oliveira RM, Pagnoncelli MGB, Rocha HAO, de Macedo GR, Dos Santos ES. Chitooligosaccharides antagonize the cytotoxic effect of glucosamine. World Journal of Microbiology and Biotechnology. 2012; 28(3): 1097-105. PMid: 22805831. https://doi.org/10.1007/s11274-011-0910-4

23. Jeon YJ, Kim SK. Production of chitooligosaccharides using an ultrafiltration membrane reactor and their antibacterial activity. Carbohydrate Polymers. 2000; 41(2): 13341. https://doi.org/10.1016/S0144-8617(99)00084-3

24. Gingras M, Paradis I, Berthod FC. Nerve regeneration in a collagen-chitosan tissue engineered skin transplanted on nude mice. Biomaterials. 2003; 24(9): 1653-61. https://doi.org/10.1016/S0142-9612(02)00572-0

25. Arpornmaeklong P, Suwatwirote N, Pripatnanont P, Oung- 
bho K. Growth and differentiation of mouse osteoblasts on chitosan-collagen sponges. International Journal of Oral and Maxillofacial Surgery. 2007; 36(4): 328-37. PMid: 17223012. https://doi.org/10.1016/j.ijom.2006.09.023
26. Qi L, Xu Z, Jiang X, Hu C, Zou X. Preparation and antibacterial activity of chitosan nanoparticles. Carbohydrate Research. 2004; 339(16): 2693-700. 